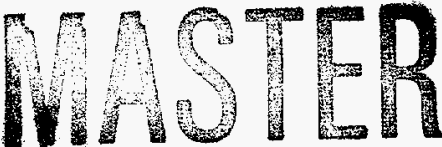

SPE 38573

\section{CONF-971006 ․}

Sandia is a multiprogram laboratory operated by Sandia Corporation, a Lockheed Martin Company, for the United States Department of Energy under contract DE-ACO4-94AL85000. \title{
.
}

\section{DISTRIBUTON OF THS DOCUMENT IS UNLIMTED}

\section{Microseismic and Deformation Imaging of Hydraulic Fracture Growth and Geometry in}

the C Sand Interval, GRI/DOE M-Site Project

N.R. Warpinski, SPE, Sandia Natl. Labs, and P.T. Branagan, SPE, and R.E. Peterson, SPE, Branagan \& Assoc., and J.E. Fix, SPE, James E. Fix \& Assoc., and J.E. Uhl and B.P. Engler, Sandia Natl. Labs, and R. Wilmer, Branagan \& Assoc.

Copyright 1997, Society of Petroleum Engineers, Inc.

This paper was prepared for presentation at the 1997 SPE Annual Technical Conference and Exhibition held in San Antonio, Texas, 5-8 October 1997.

This paper was selected for presentation by an SPE Program Committee following review of information contained in an abstract submitted by the author(s). Contents of the paper, as presented, have not been reviewed by the Society of Petroleum Engineers and are subject to correction by the author(s). The material, as presented, ooes not necessarily reflect any cosition of the Society of Petroleum Enginears, its officers, or members. Papers presented at cose meetings ace subect SPE meetings are subject to publication review by Edthi or mority of Petroleum Engineers. Electronic reproduction, distribution, or storage of any part of this paper for commercial purpases without the written consent of the Society of Petroleum Engineers is prohibited. Permission to reproduce in print is restricted to an abstract of not more than 300 words; illustrations may not be copied. The abstract must contain conspicuous acknowledgment of where and by whom the paper was presented. Write Librarian SPE P.O. Box 833836. Richardson, TX 75083-3836, U.S.A., fax 01-972-952-9435.

\section{Abstract}

Six hydraulic-fracture injections into a fluvial sandstone at a depth of $4300 \mathrm{ft}$ were monitored with multi-level tri-axial seismic receivers in two wells and an inclinometer array in one well, resulting in maps of the growth and final geometry of each fracture injection. These diagnostic images show the progression of height and length growth with fluid volume, rate and viscosity. Complexities associated with shut downs and high treatment pressures can be observed. Validation of the seismic geometry was made with the inclinometers and diagnostic procedures in an intersecting well. Fracture information related to deformation, such as fracture closure pressure, residual widths, and final prop distribution, were obtained from the inclinometer data.

\section{Introduction}

Contrary to expectations based on simple models, hydraulic fracturing is proving to be a complex process that is still not adequately represented by theory. The reason for this is clear, as models assume that the earth is a homogeneous isotropic continuum when in fact the reservoirs which are fractured are highly discontinuous and variably anisotropic and heterogeneous. Since current models are incapable of dealing with this complexity in anything but an ad hoc manner,' further understanding of hydraulic fracturing is not likely to progress very rapidly without an ability to measure, image, or observe fracturing processes under in situ reservoir conditions.

A glimpse at the complexity of fracturing in real reservoirs is now available from several cores through hydraulic fractures, ${ }^{2-4}$ from limited mineback experiments, ${ }^{5-9}$ and from various diagnostics. . $10-16$ From these relatively few measurements, complex features such as multiple fracture strands, secondary fractures, $T$-shaped fractures, redirection of fracture orientation due to production, inefficient growth across bedding, complex proppant transport, and other unexpected features have been seen. From this limited sampling, one would conclude that the fracturing process is poorly represented by most models. However, it should also be stressed that the results found at the end of a treatment (e.g., as in a cored or mined-back fracture) may not be a good representation of the actual process during fracturing, since all complexities will be seen whether or not they had any significant effect on the mechanics of the process. Separating out irrelevant features is difficult using only post-fracture snapshots of the process.

For the reasons noted above, it is clear that the optimum diagnostic would provide a real-time continuous image of the fracture growth process. Currently, there is no envisioned technology for directly viewing the fracture, but some fracture parameters can be indirectly monitored using downhole seismic receivers and downhole inclinometers. The application of these two technologies in the C-sand interval at the M-Site facility is the subject of this paper.

\section{M-Site}

The M-Site field experiments, ${ }^{17}$ located at the previous Multiwell Experiment site in the Piceance basin of Colorado, are co-funded by the Gas Research Institute (GRI) and the US Department of Energy. Details of the M-Site layout and instrumentation are given in previous papers ${ }^{4,13-15,17-20}$ and are only briefly repeated here. The reservoirs undergoing testing are fluvial Mesaverde sand-shale sequences, so the technologies developed in this difficult environment are translatable to many other reservoirs. Results of previous tests are found in several papers and reports.

A plan view of the site is shown in Figure 1 and a schematic of the well, instrument, and sandstone layout are given in Figure 2. The site consists of one treatment well $(\mathrm{MWX}-2)$, one monitor well with cemented tri-axial seismic 


\section{DISCLAMIER}

Portions of this document may be illegible in electronic image products. Images are produced from the best available original document. 


\section{DISCLAIMER}

This report was prepared as an account of work sponsored by an agency of the United States Government. Neither the United States Government nor any agency thereof, nor any of their employees, makes any warranty, express or implied, or assumes any legal liability or responsibility for the accuracy, completeness, or usefulness of any information, apparatus, product, or process disclosed, or represents that its use would not infringe privately owned rights. Reference herein to any specific commercial product, process, or service by trade name, trademark, manufacturer, or otherwise does not necessarily constitute or imply its endorsement, recommendation, or favoring by the United States Government or any agency thereof. The views and opinions of authors expressed herein do not necessarily state or reflect those of the United States Government or any agency thereof. 
receivers and bi-axial inclinometers and one cased observation well for wireline run tools (MWX-3). Also shown in the figure is an intersection well (IW-1C) with a deviated lateral that penetrates through the created hydraulic fracture(s). The openhole section of the lateral is shown as the dashed section.

The monitor well provides the instrumentation for validating the seismic results. Thirty tri-axial receiver stations, with low-noise $(<1 \mu \mathrm{g})$, wide-bandwidth $(2-2200 \mathrm{~Hz})$ accelerometers provide high quality microseismic data from which the source can be accurately located. In the same well six bi-axial tiltmeters with nanoradian resolution provide information on the mechanical deformation of the formation which is used to validate the seismic results, as well as provide valuable information related to rock deformation. The 7 -in cased observation well is used for multi-level, wireline-run, tri-axial receiver arrays of the type that will be used in a commercial fracture diagnostic service. This array uses the same accelerometers as are grouted in the monitor well, and the multi-level feature also provides for highly accurate microseismic event location. The monitor well results, with many more levels to apply in location algorithms, are used to verify the data obtained from the wireline receiver arrays.

Additional information obtained in the treatment well, such as bottom-hole pressure, spectral gamma logs of radioactive tracer distributions, and seismic surveys, are used for detailed fracture modeling and additional diagnostic information. Detailed stress, rock property and reservoir property data are also available for these reservoirs and are used for fracture models, finite element deformation models, and analyses of the mechanical response of the formation to the fracture treatment.

Additionally, crosswell seismic surveys were conducted to determine the p-wave and s-wave structure at the site. Seismic data were obtained with 5 - $\mathrm{ft}$ source and receiver spacings in the treatment and monitor well, respectively, and the permanent $30-\mathrm{ft}$ spacing of the cemented receivers in the monitor well. The seismic source was an airgun which provided excellent $\mathrm{p}$-waves and generally good s waves. Both $p$ and $s$ tomograms have been produced.

Of critical importance for validating the seismic results was the lateral well ${ }^{21}$ which intersected the expected fracture plane at a point $287 \mathrm{ft}$ from the treatment well (MWX-2) and at an elevation approximately $1 / 3$ of the thickness of the sandstone from the bottom of the sandstone.

The lithology of the $C$ sand consists of an estuarine sandstone found near the top of the Mesaverde formation. Figure 3 shows a gamma log of this sandstone taken from the treatment well. The stress contrasts around the $C$ sand, as determined primarily from microfracture stress measurements, are shown in Figure 4. Stresses in the $B$ and $C$ sands were confirmed using the inclinometers to the record the pressure at which opening begins. For modeling purposes, more detailed calibrated stress logs were also developed.

During C-sand testing, six different fracture injections using two different fluids were monitored. Important information on the injections is given in Table 1.

Table 1 Treatment Data

\begin{tabular}{|c|c|c|c|c|c|}
\hline & FRACTURE & $\begin{array}{c}\text { VOLUME } \\
(\mathrm{bbl})\end{array}$ & FLUID & $\begin{array}{c}\text { RATE } \\
(\mathrm{bpm})\end{array}$ & $\begin{array}{c}\text { SAND } \\
(\mathrm{kLB})\end{array}$ \\
\hline 1C & Breakdown & 95 & $40 \#$ X-Link & 20 & \\
\hline 2C & Approach MF & 132 & $40 \#$ Linear & 20 & \\
\hline $3 \mathrm{C}$ & Intersection MF-1 & 247 & $40 \#$ LInear & 22 & \\
\hline 4C & Intersection MF-2 & 982 & $40 \#$ X-Link & 40 & \\
\hline 5C & Diagnostic Test & 480 & $40 \#$ X-Link & 30 & \\
\hline $6 \mathrm{C}$ & Stimulation & 2118 & $40 \#$ X-Link & 30 & 250 \\
\hline
\end{tabular}

Data Analysis

Instrumentation consisted of tri-axial accelerometer arrays in both the monitor well and MWX-3 observation well and a biaxial inclinometer (tiltmeter) array in the monitor well. Data analysis consisted of location analysis of the microseismic events, from which maps of fracture growth were generated, elastic modeling of the measured inclinations from which fracture height estimates were derived, and correlation of these results with other information derived from fractureinjection and intersection-well data.

Microseisms. The analysis of the microseismic data was performed in the usual manner for a large number of receiver stations. ${ }^{10,14,15,19}$ Only events that were detected on several receivers were analyzed and used. P-wave and s-wave arrivals were selected and the particle motion of the initial $p$ wave was determined using a regression based on circular statistics. The direction to the source was found from the average particlemotion orientation, not including any obvious outliers.

The distance to and elevation of the microseismic source were found from a joint regression of the distance equations for the two phases,

and

$$
r^{2}+\left(z_{i}-z\right)^{2}=V_{p}^{2}\left(t_{p i}-t\right)^{2}
$$

$$
r^{2}+\left(z_{i}-z\right)^{2}=V_{s}^{2}\left(t_{s i}-t\right)^{2}
$$

where $r$ is the horizontal distance from the monitor well to the source, $z$ is the elevation of the source, $t$ is the time at which the microseism originated, $V_{p}$ and $V_{s}$ are p-wave and s-wave velocities, $z_{i}$ is the elevation of the $i^{\text {th }}$ receiver, and $t_{p i}$ and $t_{s i}$ are the $\mathrm{p}$-wave and s-wave arrival times at the $\mathrm{i}^{\text {th }}$ receiver. Using this approach, a best fit location of the microseism and well-defined uncertainties can be readily calculated.

Inclinometers. Inclinometer data were processed in the same manner as described in Branagan et al. ${ }^{20}$ For short-term treatment monitoring, inclinometers were zeroed at the beginning of the fracture injection and changes in the tilt field normal to the fracture (the most sensitive orientation) were continuously monitored. The resulting inclination field was immediately compared with several analytic models, including 
2-D,,$^{20}$ penny-shaped, ${ }^{20}$ and flat elliptic $\operatorname{crack}^{23}$ (3-D) geometries. A final analysis of the results generally included finite-element calculations to fully account for stress and modulus variations..$^{20}$ Important controlling parameters for the inclinations include the pressure in the fracture, fracture length, height and azimuth, the moduli of the various rock layers, and the stress in the layers contacting the fracture. Unfortunately, at the time of these tests the inclinometers were beginning to degrade (they had been in the well for two years) and the deformation data on fracture height was not as accurate as $B$ sandstone results.

Inclination data were also examined for long term residual effects (proppant placement and final propped width) and for initial opening of the fractures (to provide closure stress data).

\section{Fracture Experiments}

Fracture experiments in the $C$ sand interval (see Table 1) were conducted between August and December, 1996, and usually were spaced with several weeks between treatments to reequilibrate the reservoir, with the exception of $1 \mathrm{C}$ and $2 \mathrm{C}$ (two days) and $5 \mathrm{C}$ and $6 \mathrm{C}$ (two days).

Figure 5 shows a correlated plot of pressure data from all six injections for reference to the following diagnostic results. Closure stress is approximately $3050 \mathrm{psi}$, the overburden stress is approximately $4600 \mathrm{psi}$, and the maximum horizontal stress is at most 4200 psi in the $C$ sand.

Injection 1C (Breakdown). The first injection in the $C$ sand consisted of a $95 \mathrm{bbl}$ breakdown using a cross-linked $40 \#$ borate gel pumped at $20 \mathrm{bpm}$. The purpose of the thick fluid was to minimize pressure drops near the wellbore.

Figure 6 shows plan and side views of all of the microseismic data for this injection. The fracture appears to have grown upward about $20-30 \mathrm{ft}$, particularly on the west wing, while it has generally avoided the lower part of the $\mathrm{C}$ sand. The fracture shape is also relatively symmetric with a wing length of about $200 \mathrm{ft}$.

Additional information about hydraulic-fracture mechanisms can often be gleaned from observing the timedependent growth of the fracture. Figure 7 shows plan and side views of the microseisms recorded after 5 minutes, which is the point where shut-in occurred. At this time there are relatively few microseisms and they only show fracture growth out to $130 \mathrm{ft}$ on each wing. Thus, an additional $70 \mathrm{ft}$ of length growth occurred after shut in. The side view indicates that initial growth was within the center of the $C$ sand and above the $C$ sand on the west wing.

Relative to the intersection well, injection $1 \mathrm{C}$ resulted in a fracture which extended at most $200 \mathrm{ft}$ on the east wing. Thus there was no evidence from the microseisms that the fracture contacted the intersection well (at a distance of $287 \mathrm{ft}$ from the treatment well, MWX-2), nor was there any indication of any pressure disturbance in the intersection well.
Fracture 2C (Approach Minifracture). Injection 2C, which was conducted on August 8,1996, was designed to be a linear-gel minifrac which would approach the intersection well without hitting it. The design volume was $250 \mathrm{bbl}$ at a design rate of $20 \mathrm{bpm}$. However, recognizing that fracture growth is very uncertain in these complex fluvial geometries, it was decided that at the first sign of pressure increase in the intersection well, the treatment would be terminated.

As can be seen in the pressure data of Figure 5 , the $2 \mathrm{C}$ injection included a step-up pump at the beginning of the injection and then a quick step-down and shut-in for nearwellbore pressure-drop estimates. Finally, injection started again at about 9 minutes and continued until a pressure increase was observed in IW-IC. The maximum net pressure for this injection was about 900 psi.

The pressure increase in the intersecting well was observed after pumping $130 \mathrm{bbl}$ and the treatment was terminated with a total injected volume of $132 \mathrm{bbl}$. Details of the intersection pressure behavior are given in Branagan et al, ${ }_{2}^{21}$ but just the timing of the pressure increase provides a well defined fracture length for comparison with the microseismic results. Figure 8 shows the microseismic fracture geometry at the time that pressure was observed in the intersection well (at a distance of $287 \mathrm{ft}$ ). At the time of intersection, the microseismic length is $290 \mathrm{ft} \pm 10 \mathrm{ft}$ on the east wing, thus validating the accuracy of the microseismic length results. In this test, the west wing length is also nearly $300 \mathrm{ft}$.

Figure 9 shows the plan and side views of all of the microseisms recorded during the $2 \mathrm{C}$ injection. The injection results in an approximately $N 74^{\circ} \mathrm{W}$ azimuth with an east wing length of at least $400 \mathrm{ft}$ and a west wing that is slightly less. All of the additional growth in Figure 9, as compared to Figure 8 , occurs after shut in. On both wings, the fracture appears to avoid the lower part of the $C$ sand. There is no upward growth on the west wing of the fracture, but the east wing shows upward height growth starting about $150 \mathrm{ft}$ east of the wellbore.

As noted previously, these $2 \mathrm{C}$ microseismic results are the most important aspect of this entire $C$ sand test sequence, as this experiment proves that the microseisms provide an accurate image of fracture length. However, some interesting results with respect to fracture growth can also be seen in these data. The fracture growth upward on the east wing is somewhat unusual, as height growth is generally observed near the wellbore where the pressure is the highest. One possible explanation is the existence of additional sandstone units at the top of the $C$ sand on the east wing. Such an interpretation is supported by the cross-well seismic survey, which indicated that the $C$ sand shifted upward in the section between MWX-2 and the monitor well. Since this upper sand unit does not extend north into the treatment-well region, it is likely that it extends east-west. This hypothesis was confirmed by sedimentary analysis. Based on this interpretation, the fracture is merely following the sandstone channel and there is 
no out-of-zone growth.

The final fracture length of $400 \mathrm{ft}$ and the minimal height growth compared to injection $1 \mathrm{C}$ shows that there are significant effects due to the viscosity. At a volume of $95 \mathrm{bbl}$ of cross-linked gel, the breakdown injection achieved a final length of $200 \mathrm{ft}$. With only $40 \%$ more volume than $1 \mathrm{C}$, the linear-gel $2 \mathrm{C}$ injection achieved double the length, even while experiencing greater leakoff due to the lower viscosity and the long shut-in period. However, this difference in length extension was achieved even though net pressures differed by only 50-100 psi.

Injection 3C (Full Intersection Minifracture). Injection $3 \mathrm{C}$, which was conducted on August 21, 1996, was a repeat of injection $2 \mathrm{C}$, except that a full $247 \mathrm{bbl}$ were injected. The pressure response in and post-fracture logging of the intersection well (see Branagan et $\mathrm{al}^{21}$ ) indicated that the interconnection after the $2 \mathrm{C}$ treatment was minimal. It was hoped that this poor connection could be remedied with a larger linear-gel treatment that would more adequately intersect the IW-1C well.

The complicated pressure response during injection $3 \mathrm{C}$, as shown in Figure 5, is due to step-up, step-down, and shut-in periods. Most of the volume was injected in the latter part of the test at a rate of $22 \mathrm{bpm}$ and a net pressure of about 950 psi.

Microseismic results of injection $3 \mathrm{C}$ are shown in plan and side view in Figure 10. This fracture has an injected volume of only $250 \mathrm{bbl}$ and a fairly high leakoff because it is a linear gel, yet the fracture lengths are almost $500 \mathrm{ft}$ on the east wing and more than $400 \mathrm{ft}$ on the west wing. The azimuth through all three initial injections have been $N 74^{\circ} \mathrm{W}$ or $N 75^{\circ} \mathrm{W}$. This fracture shows some slight evidence of height growth near the wellbore. The upward growth on the far east wing, which was first seen in the $2 \mathrm{C}$ injection, is also obvious in this test.

The intersection with IW-1C (pressure increase in the intersection well) occurred relatively early in the treatment, but, as in injection $2 \mathrm{C}$, it was not a very conductive connection. The microseisms suggest that the hydraulic fracture may have been mostly above the intersection well, since little microseismic activity occurred in the lower $C$ sand on the east wing. This test also showed the rising fracture behavior on the east wing, but it is obscured somewhat by the increased height growth near the wellbore.

The inclinometers provided important long-term information about residual deformation after unpropped fracture treatments. Figure 11 shows the inclinations recorded on the shallowest inclinometer during and after the $1 \mathrm{C}-3 \mathrm{C}$ injections. These data have been normalized to the largest value ( $3 \mathrm{C}$ maximum value) and show that the deformation never returns to zero, but instead maintains a nearly $20 \%$ residual expansion. This expansion is interpreted as being primarily a result of residual opening, as poro-elastic effects would have disappeared after reservoir pressure equilibration was complete (typically a few days). It can also be seen that the magnitudes of the tidal inclinations are much smaller than the inclination magnitudes induced by the fracture treatments and, thus, do not cause any interpretation problems in this downhole environment.

Injection 4C (High Energy Intersection). Injection 4C, conducted on November 22, 1996, was a dual objective test. Approximately $1000 \mathrm{bbl}$ of $40-\mathrm{LB} / \mathrm{mgal}$ cross-linked gel were injected into the $C$ sand at about $40 \mathrm{bpm}$ in order to provide the opportunity for obtaining treatment well diagnostics and to give a final attempt at obtaining a clear intersection of IW-1C. To test the treatment well diagnostics, a four-level seismic array was placed in the treatment well, straddled over the $C$ sand. Unfortunately, during initial injection of water in the casing, the turbulence of the thin fluid induced sufficient vibration to loosen a locking nut on the fiber-optic cable head, causing a break in the copper and fiber-optic lines (but the cable armor remained connected and there was not a complete disconnect of the tool string). Thus, no treatment well diagnostics were obtained during this test and the remaining diagnostics were based on data from the monitor-well receivers.

The injection consisted of the pre-injection of $132 \mathrm{bbl}$ of $\mathrm{KCl}$ water, which was in the casing originally, followed by the injection of the cross-linked gel in two stages, separated by a 15. minute shut-in period for leakoff and near-wellbore analyses. As seen in Figure 5, the injection of the gel occurs for about 15 minutes, followed by a 15 minute shut down.

The microseisms recorded after the first gel injection and shut-in period are shown in Figure 12. These data indicate that considerable height growth occurred on the west wing during this period, as well as length extension on the order of $300 \mathrm{ft}$. The additional height growth is not surprising, since the net pressure was greater than 1100 psi during the injection period. There is also an interesting secondary feature running to the north-northeast. Although it was speculated that this feature could be a secondary fracture or activated fault, it was not considered important until after the $6 \mathrm{C}$ injection showed the same feature and additional complexity as a result of it.

Gel injection resumed at about 30 minutes, but at first the gel would not move and surface pressures reached their maximum allowable at rates of only 1-2 bpm. Finally the fluid started to move and rates were eventually built to their design values. However, at the point where the gel began moving and fracturing clearly restarted, there was a large burst of microseismic activity and a clear pressure connection was observed in the intersecting well. Net pressures varied considerably during the treatment, but an average net pressure after fracturing resumed following the shut-in period is roughly 1200 psi.

All of the microseisms from the $4 \mathrm{C}$ injection are shown in plan view and side in Figure 13. Fracture $4 \mathrm{C}$ is clearly an asymmetric fracture with considerable height growth. The east wing length is $600-700 \mathrm{ft}$ while the west wing is only about 
$400 \mathrm{ft}$. This asymmetry occurred after the shut-in period and suggests that fracture extension was affected by the shut-in process, essentially redirecting growth in the easterly direction with little extension along the west wing. Fracture growth upward is $60-80 \mathrm{ft}$, depending on the location, while growth downward is about $50 \mathrm{ft}$, but primarily on the west wing.

Since injection $4 \mathrm{C}$ exhibited significant height growth, it is a good test case for evaluation by the inclinometer array. Figure 14 shows the maximum $4 \mathrm{C}$ inclination data at each of the six stations during the injection, as compared to 2-D finite element modeling based on a 1200 psi treatment pressure. The mesh and layering used are the same as were employed for the B sandstone tests. ${ }^{20}$ Only a 2-D case was used because the fracture length on the east wing is $700 \mathrm{ft}$ and previous analyses had shown that after $600 \mathrm{ft}$ of length, there was no significant difference between the 2-D and 3-D models.

Although the data cannot be exactly matched, it is clear that the fracture height on this wing is on the order of 130$140 \mathrm{ft}$, very comparable to the microseismic results. For this calculation, all of the height growth was upward. The $\mathrm{C}$ sand results again show that the microseismic heights are nearly the same as the mechanical heights, an important validation point.

Injection 5C (Treatment-Well Diagnostic Test). Injection $5 \mathrm{C}$ was intended to be a treatment-well diagnostic test where a 4-level accelerometer-based receiver system was run in the treatment well to monitor an injection from the rat hole below the perforations. As such, only $480 \mathrm{bbl}$ of $40-\mathrm{LB} / \mathrm{mgal}$ crosslinked gel were injected, at a rate of $30 \mathrm{bpm}$. Treatment pressure for this test are shown in Figure 5, but there are no unusual features other than the relatively high net pressure (1400 psi net pressure).

Data were obtained from the treatment-well array, but are still undergoing analysis and are not given here. However, the monitor-well instrumentation recorded data from this fracture and shows very simple fracture behavior, compared to the previous test.

Figure 15 gives the plan view and side view plots of the microseisms measured from the monitor well alone. These data indicate that the fracture grew very symmetrically, with lengths of nearly $500 \mathrm{ft}$ on both wings and approximately $30 \mathrm{ft}$ of both upward and downward height growth. This fracture is of interest because of its lack of complexity, in contrast to the previous test, and also because of the comparable length to the $3 C$ injection, even though the $3 \mathrm{C}$ injection employed only half of the fluid used in the $5 \mathrm{C}$ test. The primary difference between the two tests was the fluid viscosity, although injection $5 \mathrm{C}$ was pumped at a somewhat higher rate.

Injection 6C (Stimulation) Injection 6C was a propped treatment of a size typically performed per interval in this basin. $250,000 \mathrm{LB}$ sand and $2118 \mathrm{bbl}$ of $40-\mathrm{LB} / \mathrm{mgal}$ borate cross-linked fluid were injected at $30 \mathrm{bpm}$. The pressure data for this injection are also shown in Figure 5. The shape of the pressure record appears normal, but the final net pressure level of 1900 psi is well above both the maximum horizontal in situ stress and the overburden stress.

The microseismic activity after 15 minutes of injection is shown in Figure 16. By this time the fracture had extended at least $300 \mathrm{ft}$ on each wing, but, more importantly, a clear secondary fracture(s) had propagated to the northeast and another secondary fracture may have extended more northerly. There is a large degree of certainty that these are secondary fractures because they are so much farther removed from the known fracture plane than any other microseisms detected previously (except for the initial detection of this same feature in the $4 \mathrm{C}$ injection). They also begin to occur after the net pressure exceeds the maximum horizontal stress. At this time, the fracture is also relatively well contained within the $\mathrm{C}$ sand.

The final microseismic image is shown in Figure 17. By the end of the treatment, the imaging showed several levels of complexity that are most easily seen in a time-history visualization, but will be briefly described here. The secondary fracture propagating to the northeast apparently spawned one or more fractures that propagated in the same orientation as the primary fracture. These additional features occurred mostly during the first half of the treatment.

Later in the $6 \mathrm{C}$ treatment, however, microseismic activity fanned over a wide area to the south of the east fracture wing. As seen in the edge-on view of Figure 18, all of this activity (left side of plot) occurs in a narrow region at the top of the $C$ sand. This type of activity is most likely a horizontal fracture, but could also be several vertical fractures propagating in a narrow zone at the top of the sandstone. It begins to occur after the injection pressure exceeds the overburden stress.

Figure 19 shows the inclination distribution at several times from shut-in through closure. These distributions have been normalized by the maximum inclination at each time and can only be compared relative to each other. If the prop remains suspended in the fluid through closure, then the normalized distribution of the inclinations should not change with time, as only the absolute magnitude of the inclinations should change as the fracture slowly closes on an amount of proppant proportional to its width. If, however, all of the proppant falls out to the bottom of the fracture, then the shape of curves at later times will differ significantly from the original shape at shut in. As can be seen here, there is only a small difference in the shapes of the various curves, and it can be inferred that only small amounts of proppant have fallen out or convected to the bottom of the fracture.

Figure 20 shows a longer-term view of the inclinations measured by the top inclinometer for both injections $4 \mathrm{C}$ and 6C. The residual inclinations for injection $4 \mathrm{C}$, an unpropped treatment, are about $15 \%$ of the maximum values. The residual inclinations after injection $6 \mathrm{C}$ remain at about $30 \%$ of the maximum width (which was very large due to the high net pressure). The much larger residual width after injection $6 \mathrm{C}$ is 
due, to the propped width of the fracture (about 0.35 in, based on the maximum fracture width predicted by FRACPRO ${ }^{\mathrm{TM}}$ ).

\section{Discussion}

As this series of tests completes the M-Site field experiments, the main diagnostic objective of validating the accuracy and reliability of the microseismic method has been achieved. By using the array of inclinometers, intersecting-well information, and much other data, it is clear that in formations where microseismic activity is induced by a hydraulic fracture, a map of this activity provides a reliable image of the fracture.

The $\mathrm{C}$ sand experiments had as their primary diagnostic objective the determination of the accuracy of the microseismic length through a correlation of the imaged data with the intersection of a lateral wellbore. This intersection was achieved on the $2 \mathrm{C}$ injection and showed that the imaged length was correct within the accuracy limits of the technique.

Previous $M$-Site results ${ }^{15}$ had shown that microseismic heights and azimuths were also correct within their accuracy limits. In addition, the fracture azimuth was found to closely agree with the previously determined stress orientation. ${ }^{24}$

While the primary purpose of the inclinometer array (downhole tiltmeter array) was to provide validation of the microseismic results by measuring the mechanical response of the rock to the hydraulic fracture, it was also found that the inclinometers can be a very useful tool for fracture diagnostics. In addition to the accurate height measurements, the inclinometer array has been found to be valuable for determining the residual width of the fractures and the final propped width distribution relative to the original fracture width distribution. In addition, the inclinometer is a very precise instrument for measuring fracture opening, and thus closure stress.

These tests, along with previous results, ${ }^{15}$ have shown that the fracture height determined by models is not particularly accurate. There are clearly many additional mechanisms affecting height growth that have not been incorporated adequately into models. Diagnostic results such as these can be used to aid in improving the model capabilities.

The series of tests using both linear and cross-linked gels also shows that there is a significant viscosity effect. Comparing treatments $1 \mathrm{C}$ and $2 \mathrm{C}$, it is found that the lineargel fracture resulted in $100 \%$ more length growth for only $40 \%$ more fluid, even though there was higher leakoff of the linear gel. Comparing treatments $3 \mathrm{C}$ and $5 \mathrm{C}$, it was found that comparable lengths were obtained for both treatments even though the cross-linked gel had twice the fluid volume. While tip effects may still be important in fracturing, it is clear that viscosity has an important role in fracture extension. In particular, thin-fluid fractures achieve fast length extension with little height growth, a feature that could be used with great advantage to optimize fracturing procedures. On the other hand, it is not clear why such different behavior was not always reflected in the net pressure. Again, it appears that there are some elements of fracturing that are not entirely understood. Diagnostic results such as these can provide valuable data to improve model results.

The experiments have also demonstrated that the microseismic method is accurate for measuring large-scale complexity in fracture treatments. While small-scale complexities such as multiple parallel strands cannot be detected, ${ }^{25}$ the large scale complexities such as secondary fractures and horizontal fractures are readily apparent (e.g., injection $6 \mathrm{C}$ ). It is also noteworthy that the secondary vertical fractures occurred after the injection pressure exceeded the maximum horizontal stress and the horizontal features occurred after the pressure exceeded the overburden stress.

The measurement of residual fracture deformation by the inclinometers offers important insight into the successful implementation of water fractures (no prop). The large residual deformations, interpreted as fracture width, shows that significant widths can remain even without proppant. The interpretation of the residual deformation as width is due to the careful monitoring of reservoir pressure to ascertain that the effect is not due to poro-elastic behavior. Although the effect could be due to anelastic behavior, we hope that this is not the case as it would invalidate all fracture models, reservoir mechanics models, tiltmeter analyses, stress logs, and many other calculations which require elastic behavior of the reservoir.

The inclinometers have also been used for determining changes in the proppant distribution, an important element for evaluating convection and prop transport. In the two experiments at $\mathrm{M}$-Site, little indication of dropout or convection has been observed.

With regard to fracture models, these diagnostic techniques cannot provide details on fracture mechanisms (e.g., multiple fractures, tip effects, fissure opening, etc.), but the overall image of the fracture does allow for accurate testing of model accuracy in given reservoirs. It is expected that such results will require modelers to re-examine the implementation of many mechanisms related to height growth, net pressure, and prop transport. Models are important elements in any fracturing design/analysis program and any improvements in models based on imaging will pay valuable dividends in both hydrocarbon recovery and economics.

Finally, the value of imaging technology should be readily apparent to all companies involved in fracturing reservoirs. It can provide immediate benefits in designing the well layout for new fields and infill operations, for the optimization of multi-zone completions, and for the evaluation of problem reservoirs.

\section{Conclusions}

Hydraulic-fracture imaging using the microseismic method has been shown to be an accurate technique for monitoring fracture growth and determining the final size and shape of the 
fracture. Fracture length, height, and azimuth have been validated using other technology at M-Site. ${ }^{15}$

An inclinometer array (downhole tiltmeter array) has been found to provide important information on fracture parameters not readily measured using microseisms or other available diagnostic information. New features measured include residual widths, final prop placement, and closure stress.

Results at M-Site show that fracture height is much more complicated than currently implemented in models and that viscosity has a significant effect on fracture growth. In addition, these field results provide proof of complex fracture growth when pressures exceed the maximum horizontal or the overburden stress values. As imaging results become more widely available and are incorporated into model enhancements, hydraulic-fracture optimization should improve accordingly.

These diagnostic techniques should be of value for new fields, infill drilling programs, multi-zone completions and any problem reservoirs.

\section{Nomenclature}

$r=$ horizontal distance to source, $\mathrm{L}, \mathrm{ft}$

$z=$ elevation of source, $\mathrm{L}, \mathrm{ft}$

$t=$ time of microseism origination, $t, \mathrm{sec}$

$V_{p}=\mathrm{p}$-wave velocity, $\mathrm{L} / \mathrm{t}$, ft/sec

$V_{s}=$ s-wave velocity, $\mathrm{L} / \mathrm{t}, \mathrm{ft} / \mathrm{sec}$

$z_{i}=$ elevation of $\mathrm{i}^{\text {th }}$ receiver, $\mathrm{L}, \mathrm{ft}$

$t_{p l}=\mathrm{p}$-wave arrival time at $\mathrm{i}^{\text {th }}$ receiver, $\mathrm{t}$, sec

$t_{S i}=\mathrm{s}$-wave arrival time at the $\mathrm{i}^{\text {th }}$ receiver, $\mathrm{t}, \mathrm{sec}$

\section{Acknowledgments}

These experiments were conducted under funding by the Gas Research Institute, managed by Steve Wolhart, and by the Department of Energy, managed by Jim Ammer at FETC. The authors would like to acknowledge the support provided by both Steve and Jim and would like to thank Dick Myal and Rob Zeis of CER Corporation for their dedicated help, BOLT Technology Corp. for their fielding of the multi-level wireline receiver array, and the many service companies involved in these tests.

\section{References}

1. Warpinski, N.R., Moschovidis, Z.A., Parker, C.D. and AbouSayed, I.S. (1994). Comparison study of hydraulic fracturing models test case: GRI staged field experiment 3. SPE Production \& Facilities, 46, 7-16.

2. Warpinski, N.R., Lorenz, J.C., Branagan, P.T., Myal, F.R. and Gall, B.L.: "Examination of a Cored Hydraulic Fracture in a Deep Gas Well," SPE Production \& Facilities, 46, 150-158, August 1993.

3. Fast, R.E., Murer, A.S. and Timmer, R.S.: "Description and Analysis of Cored Hydraulic Fractures, Lost Hills Field, Kern County, California," SPE 24853, 67th Annual Technical Conference \& Exhibition, Washington, D.C., П, 895-908, 1992.

4. Branagan, P.T., Peterson, R., Warpinski, N.R. and Wright, T.B., "The Characterization of Remotely Intersected Set of Hydraulic
Fractures: Results of Intersection Well No. 1: GRI/DOE MultiSite Project," SPE 36452, SPE Annual Tech. Conf. \& Exh., Denver, CO, Oct. 6-9, 1996.

5. Warpinski, N.R and Teufel, L.W.: "Influence of Geologic Discontinuities on Hydraulic Fracture Propagation," JPT, 39, 209-220, Feb. 1987.

6. Warpinski, N.R.: "Measurement of Width and Pressure in a Propagating Hydraulic Fracture," SPEJ, 46, February 1985.

7. Jeffrey, R.G., Brynes, R.P, Lynch, P.A. and Ling, D.J.: "An Analysis of Hydraulic Fracture and Mineback Data for a Treatment in the German Creek Coal Seam," paper SPE 24362, SPE Rocky Mountain Regional Mtg., Casper, WY, 1992.

8. Jeffrey, R.G., Enever, J.R., Ferguson, T., Bride, J., Phillips, R. and Davidson, S.: "Small-Scale Hydraulic Fracturing and Mineback Experiments in Coal Seams," paper 9330, 1993 International Coalbed Methane Symposium, U. of Alabama, Tuscaloosa.

9. Jeffrey, R.G., Settari, A. and Smith, N.P.: "A Comparison of Hydraulic Fracture Field Experiments, Including Mineback Geometry Data, with Numerical Fracture Model Simulations," paper SPE 30508, SPE Annual Technical Conference \& Exhibition, Dallas, TX, 591, 1995.

10. Albright, J.N. and Pearson, C.F., "Acoustic Emissions as a Tool for Hydraulic Fracture Location: Experience at the Fenton Hill Hot Dry Rock Site," SPEJ, August 1982, 523.

11. Vinegar, H.J. et al., "Active and Passive Seismic Imaging of a Hydraulic Fracture in Diatomite," JPT, Jan. 1992, 28.

12. Truby, L.S., Keck, R.G. and Withers, R.J., "Data Gathering for a Comprehensive Hydraulic Fracture Diagnostic Project: A Case Study," paper SPE 27506, proc., 1994 IADC/SPE Drilling Conf., Dallas, TX, Feb. 15-18.

13. Peterson, R. et al. "Results of Multi-Sites Experimentation in the A Sand Interval: Fracture Diagnostics, Fracture Modeling and Crosswell Tomography," GRI Topical Report, GRI95/0066, April, 1995.

14. Warpinski, N.R., Engler, B.P., Young, C.J., Peterson, R., Branagan, P.T. and Fix, J.E. (1995). Microseismic mapping of hydraulic fractures using mult-level wireline receivers. Paper SPE 30507, SPE Annual Technical Conference and Exhibition, Dallas, TX, $\Delta, 579-589$.

15. Warpinski, N.R., Wright, T.B., Uhl, J.E., Engler, B.P., Drozda, P.M. and Peterson, R.E. (1996). Microseismic monitoring of the B-sand hydraulic fracture experiment at the DOE/GRI MultiSite project. SPE 36450, 1996 SPE Annual Technical Conference \& Exhibition, Denver, CO, $\triangle, 327-335$.

16. Wright, C.A. and Conant, R.A. (1995). Hydraulic fracture reorientation in primary and secondary recovery from low permeability reservoirs. SPE 30484, SPE Annual Technical Conference \& Exhibition, Dallas, TX, П, 357-369.

17. Peterson, R.E., Wolhart, S.L., Frohne, K.-H., Warpinski, N.R., Branagan, P.T. and Wright, T.B., "Fracture Diagnostics Research at the GRIDOE Multi-Site Project: Overview of the Concept and Results," SPE 36449, proc., SPE Annual Tech. Conf. and Exh., Denver, CO, Oct. 6-9, 1996.

18. Middlebrook, M., Peterson, R., Warpinski, N.R., Engler, B., Sleefe, G., Cleary, M, Wright, T. and Branagan, P., "Multi-Site Project Seismic Verification Experiment and Assessment of Site Suitability," GRI Topical Report, GRI-93/0050, Feb. 1993.

19. Sleefe, G.E., Warpinski, N.R. and Engler, B.P., "The Use of Broadband Microseisms for Hydraulic Fracture Mapping," SPE 
Formation Evaluation, Dec. 1995, 233-239.

20. Branagan, P.T., Warpinski, N.R., Engler, B.P., Wilmer, R., "Measuring the Hydraulic Fracture-Induced Deformation of Reservoir and Adjacent Rocks Employing a Deeply Buried Inclinometer Array: GRI/DOE Multi-Site Project," SPE 36451, SPE Annual Tech. Conf. \& Exh., Denver, CO, Oct. 6-9, 1996.

21. Branagan, P.T, Peterson, R.E, Warpinski, N.R., Wolhart, S.L. and Hill, R.E.: "Propagation of a Hydraulic Fracture into a Remote Observation Wellbore: Results of C-sand Experimentation at the GRI/DOE M-Site Project," SPE 38574, SPE Annual Technical Conference \& Exhibition, San Antonio, October 1997.

22. England, A.H. and Green, A.E. (1963). Some two-dimensional punch and crack problems in classical elasticity. Proceedings, Cambridge Philosophical Society, 59, 489-500.

23. Green, A.E. and Sneddon, I.N. (1950) The distribution of stress in the neighbourhood of a flat elliptical crack in an elastic solid. Proceedings Cambridge Philosophical Society, 46, 159-163.

24. Warpinski, N.R. and Teufel, L.W., "In situ Stresses in LowPermeability Nonmarine Rocks," JPT, April 1989, 405.

25. Warpinski, N.R., "Interpretation of Hydraulic Fracture Mapping Experiments," paper SPE 27985, proc., Tulsa Centennial Petroleum Engineering Symp., Tulsa, OK, Aug. 1994, 291.

\section{SI Metric Conversion Factors}

$$
\begin{array}{rlrl}
\mathrm{ft} \times 3.048^{*} & \mathrm{E}-01 & =\mathrm{m} \\
\text { in } \times 2.54^{*} & \mathrm{E}+00 & =\mathrm{cm} \\
\mathrm{bbl} \times 1.589873 & \mathrm{E}-01 & =\mathrm{m}^{3} \\
\mathrm{LB} \times 4.448222 & \mathrm{E}+00 & =\mathrm{N} \\
\mathrm{psi} \times 6.894797 & \mathrm{E}+00 & =\mathrm{kPa} \\
\mathrm{bpm} \times 9.539238 & \mathrm{E}+00=\mathrm{m}^{3} / \mathrm{s} \\
\mathrm{gal} \times 3 . .785412 & \mathrm{E}-03=\mathrm{m}^{3}
\end{array}
$$

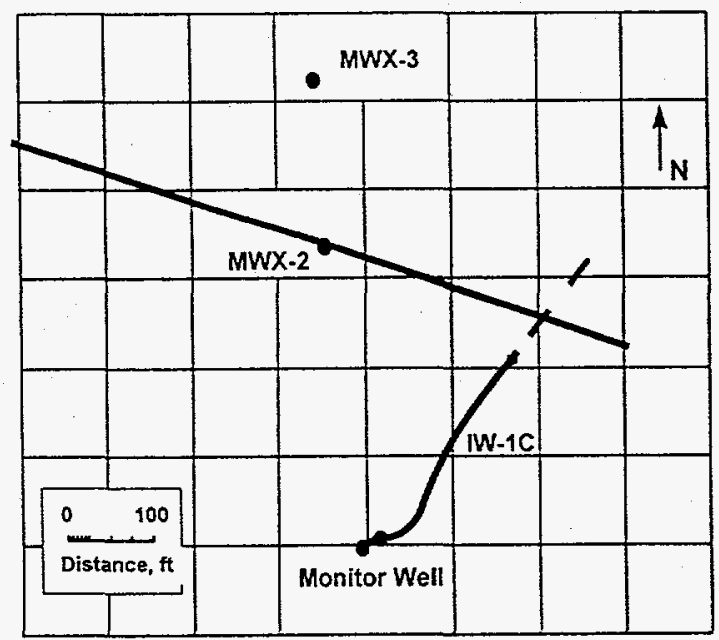

Figure 1. Plan view of M-Site.

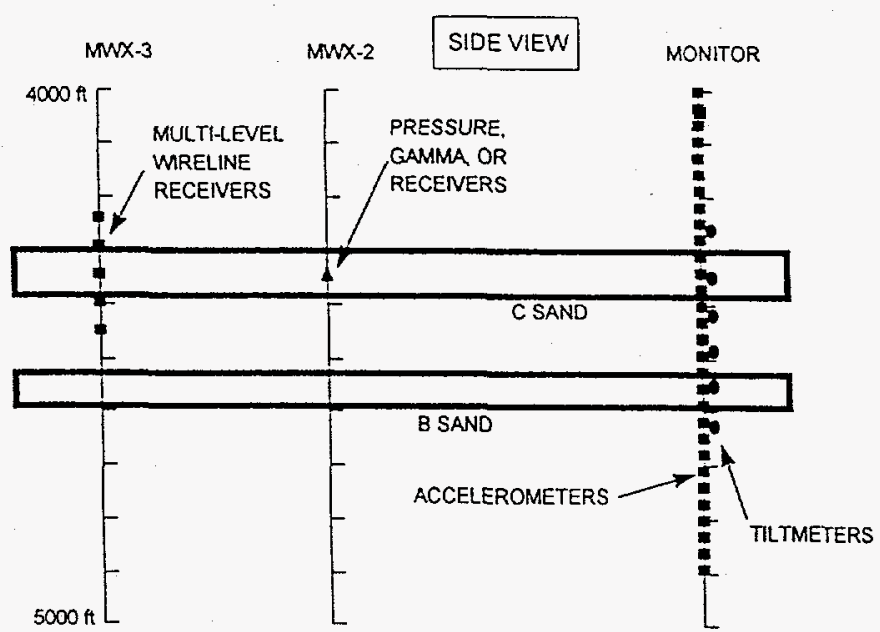

Figure 2. Layout of M-Site wells and instrumentation

\section{GAMMA RAY (API UNITS)}

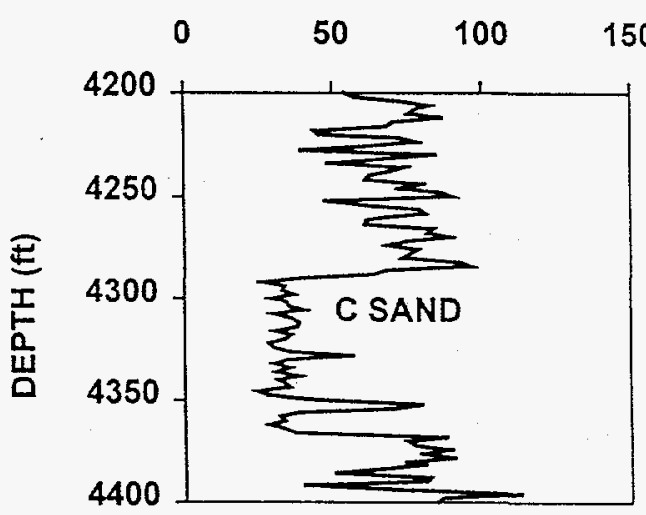

Figure 3. Gamma ray log showing $C$ sand lithology

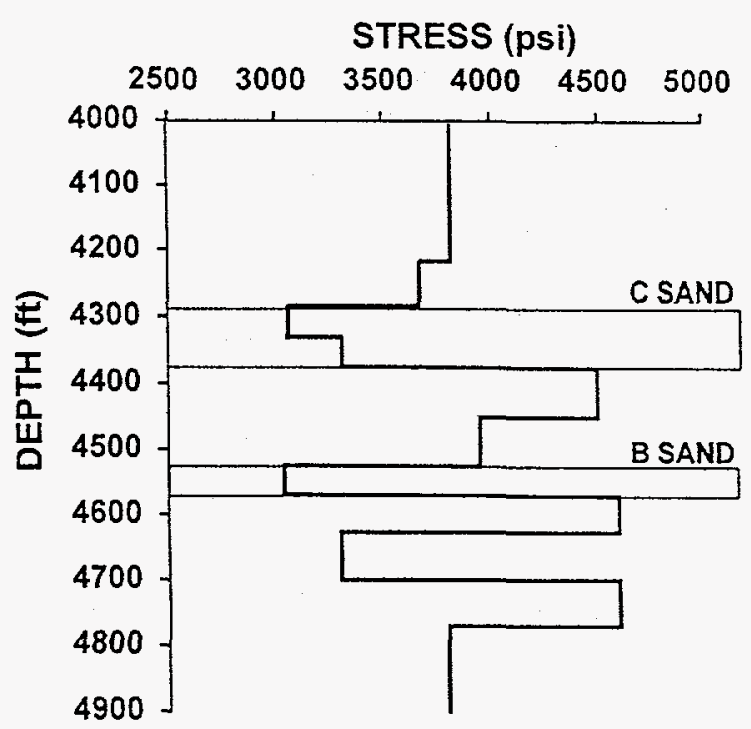

Figure 4. Stress contrasts around $C$ sand 


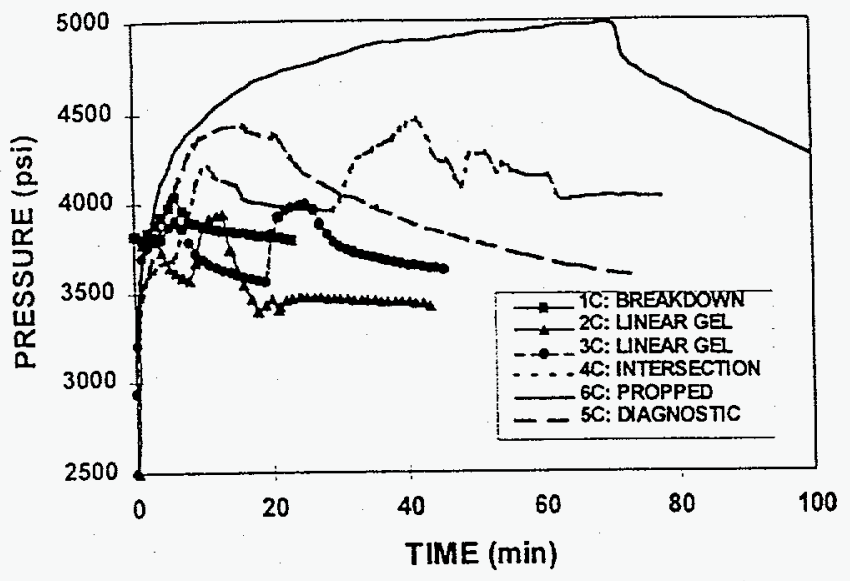

Figure 5. Correlated pressure data for $\mathrm{C}$ sand injections.
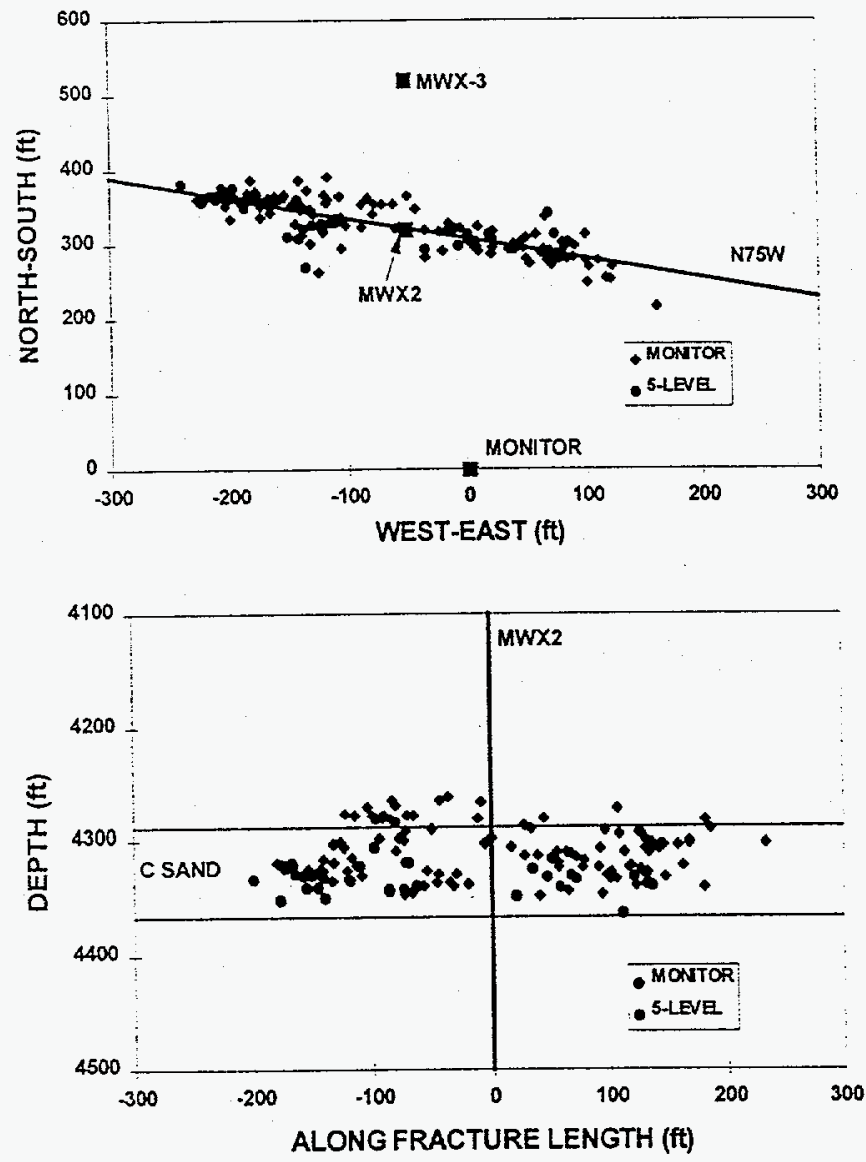

Figure 6. All injection $1 \mathrm{C}$ microseisms.
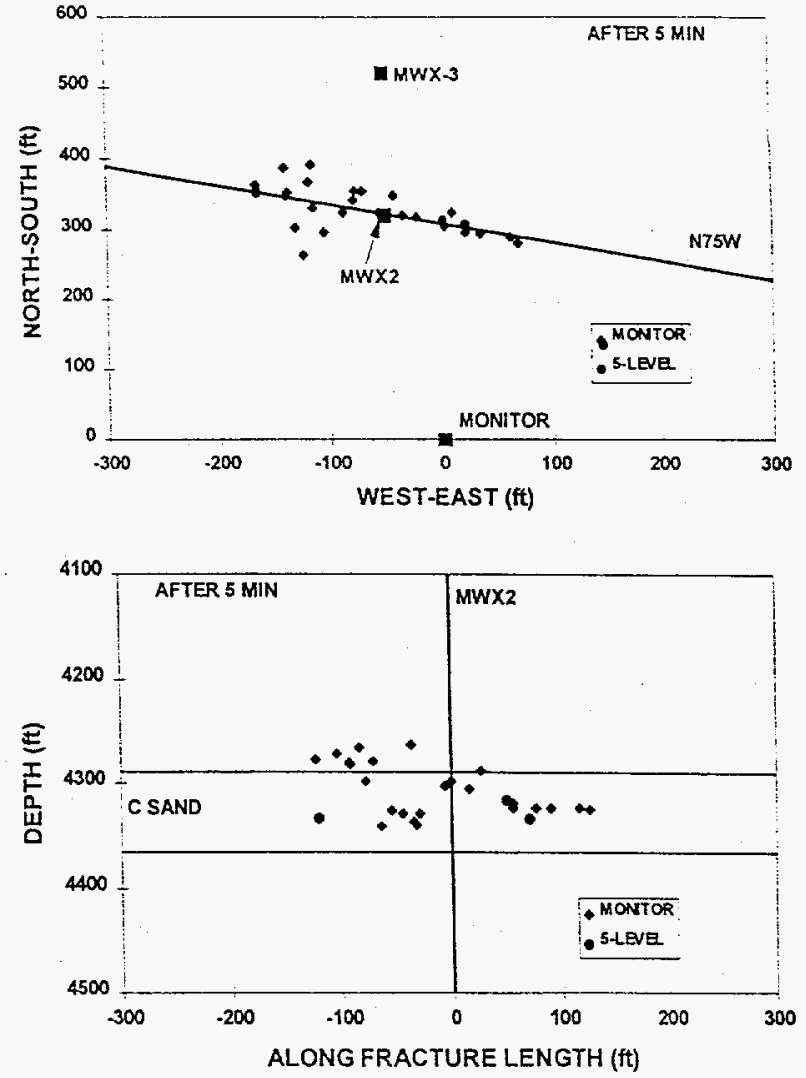

Figure 7. Injection 1C microseisms after 5 minutes (shut in).
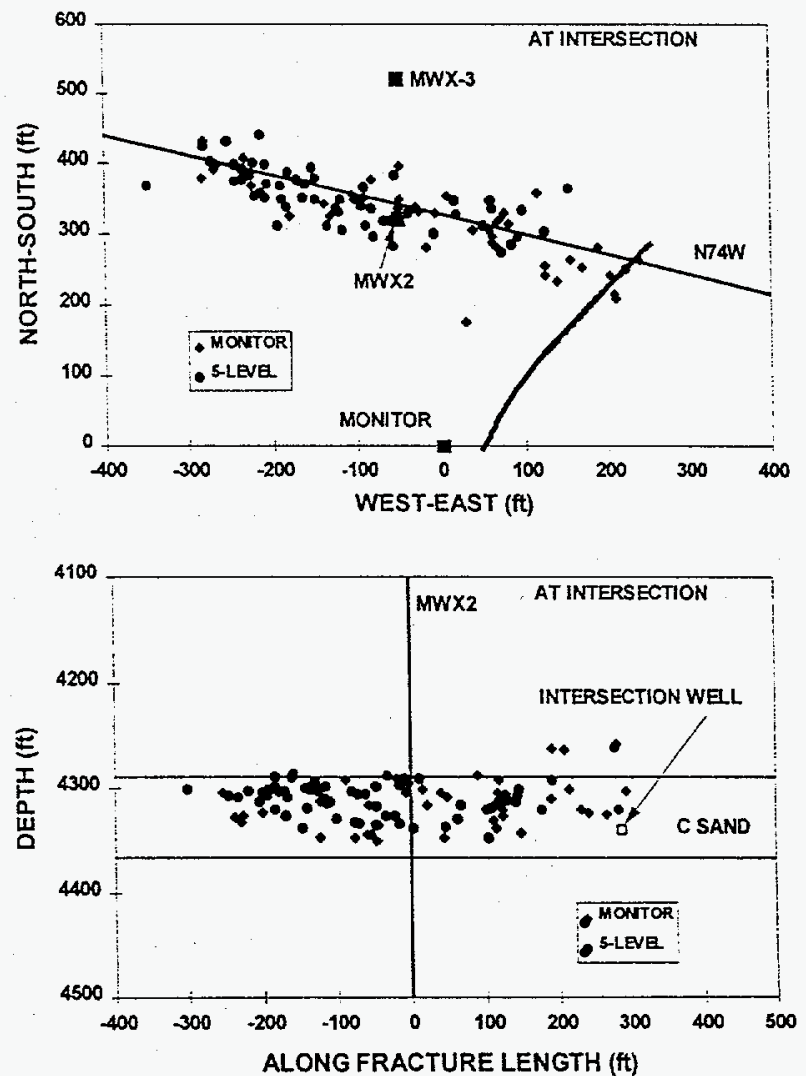

Figure 8. Injection $2 \mathrm{C}$ microseisms at intersection. 

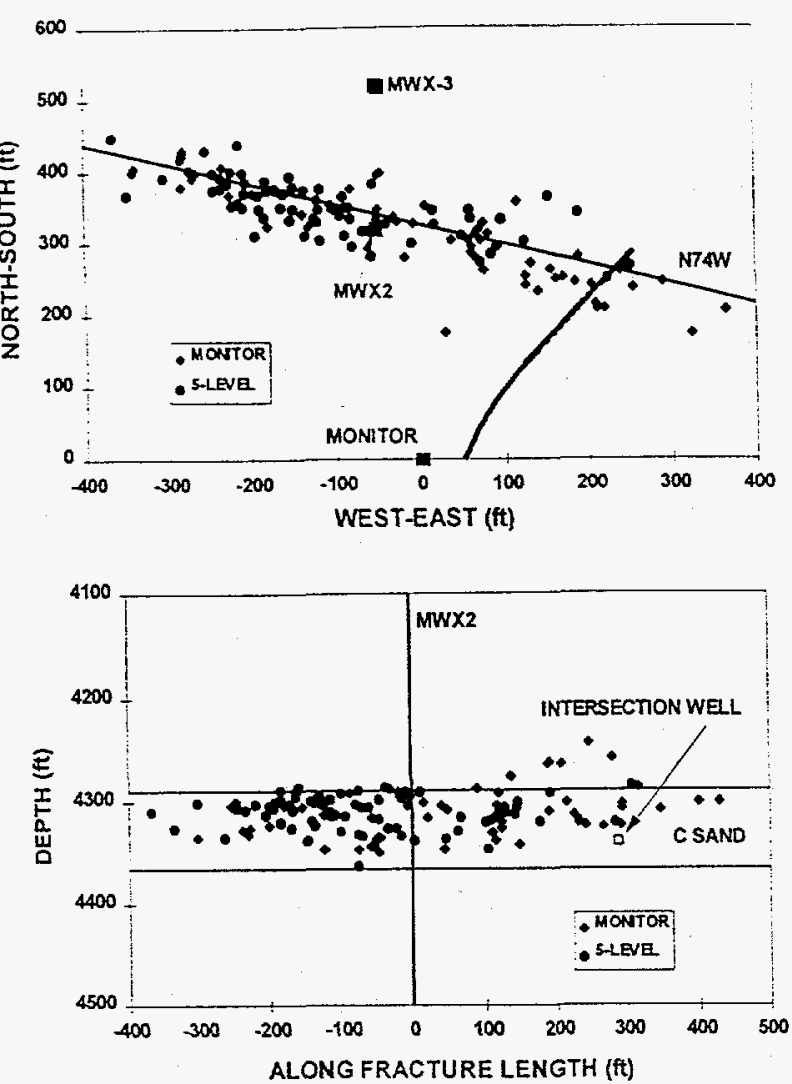

Figure 9. All injection $2 \mathrm{C}$ microseisms.
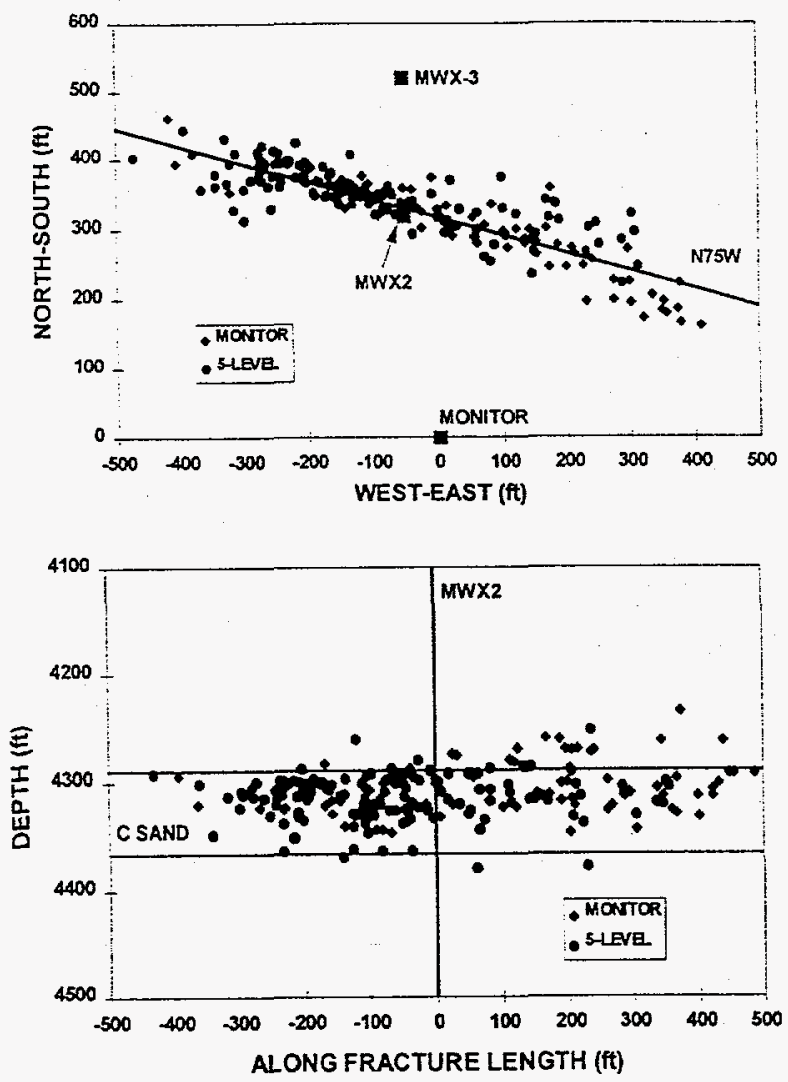

Fig 10. All injection $3 \mathrm{C}$ microseisms.

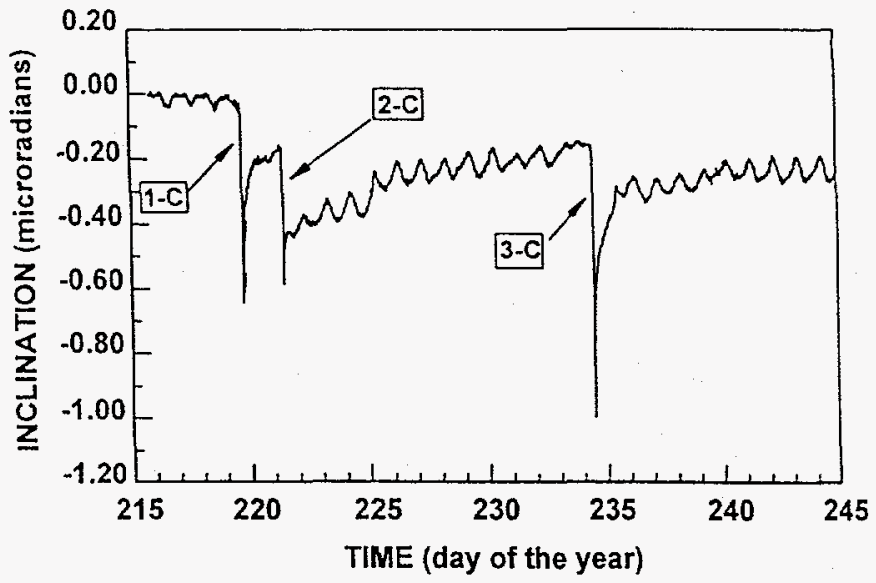

Figure 11. Long term inclinations after unpropped fractures.
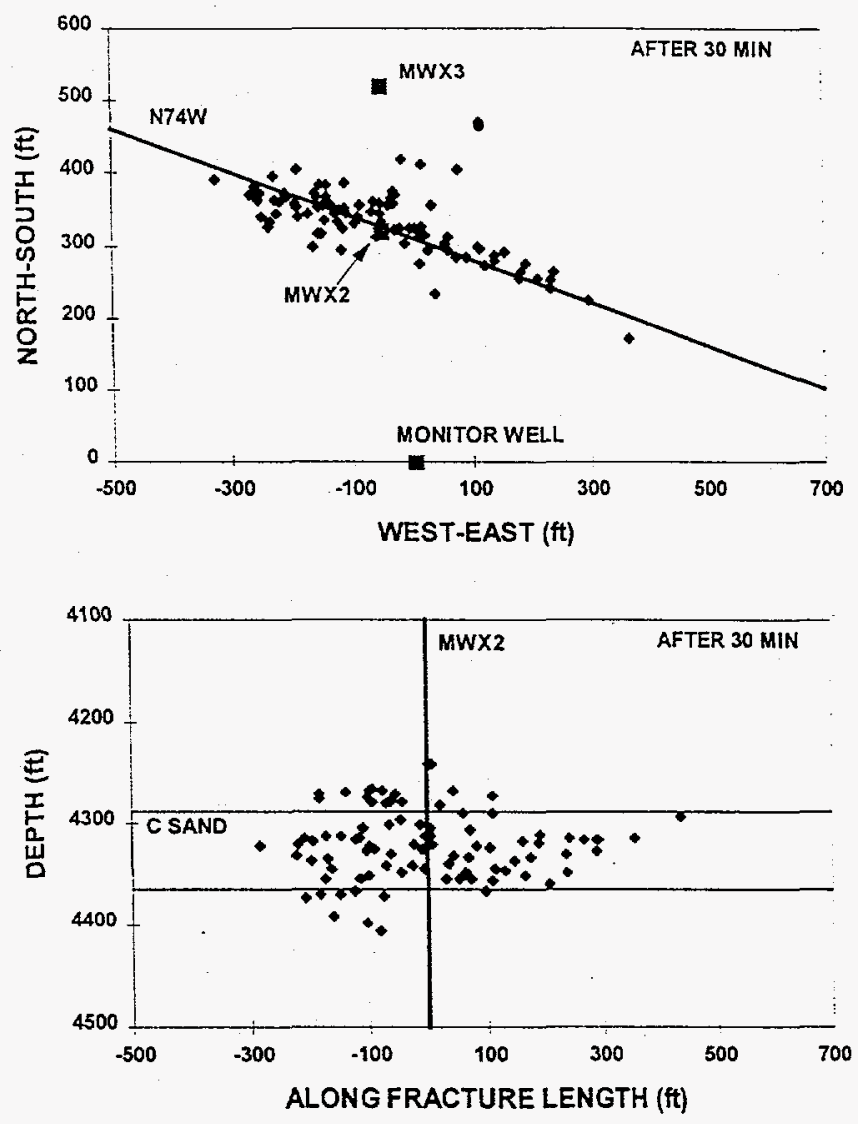

Figure 12.Injection 4C microseismic image prior to restart. 

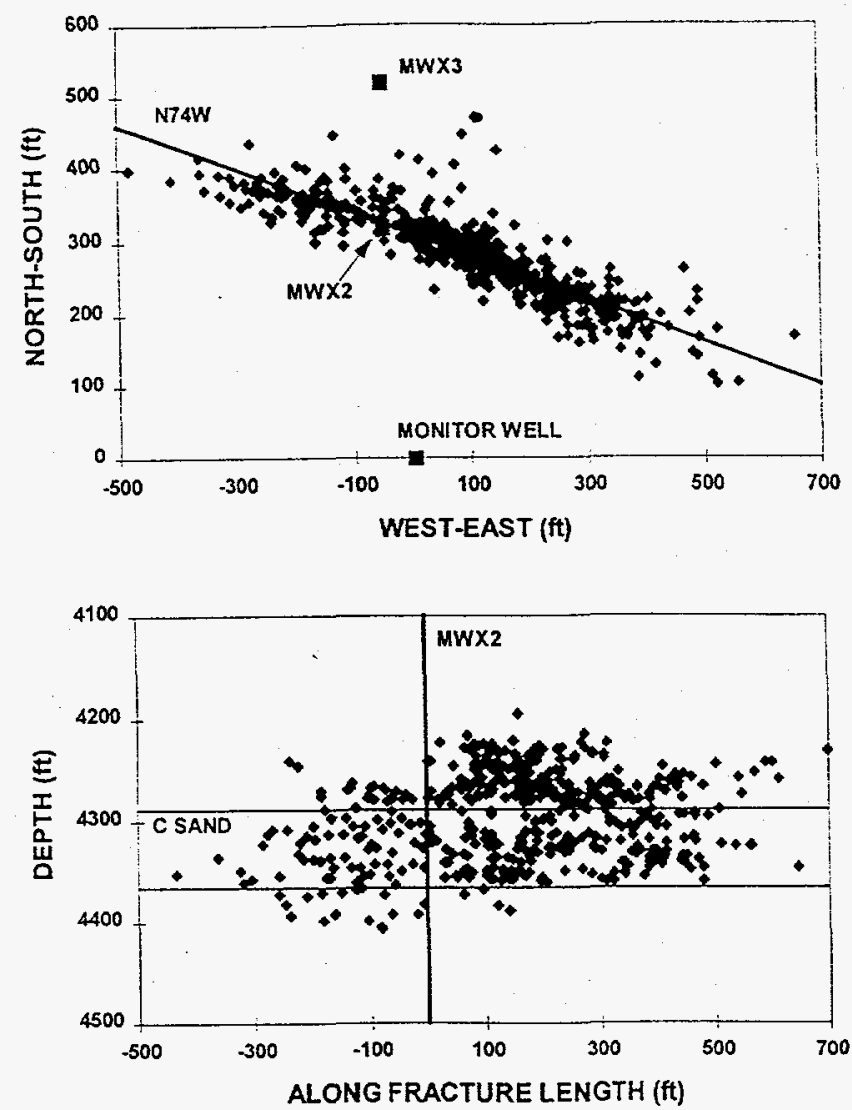

Figure 13. All injection $4 \mathrm{C}$ microseisms.

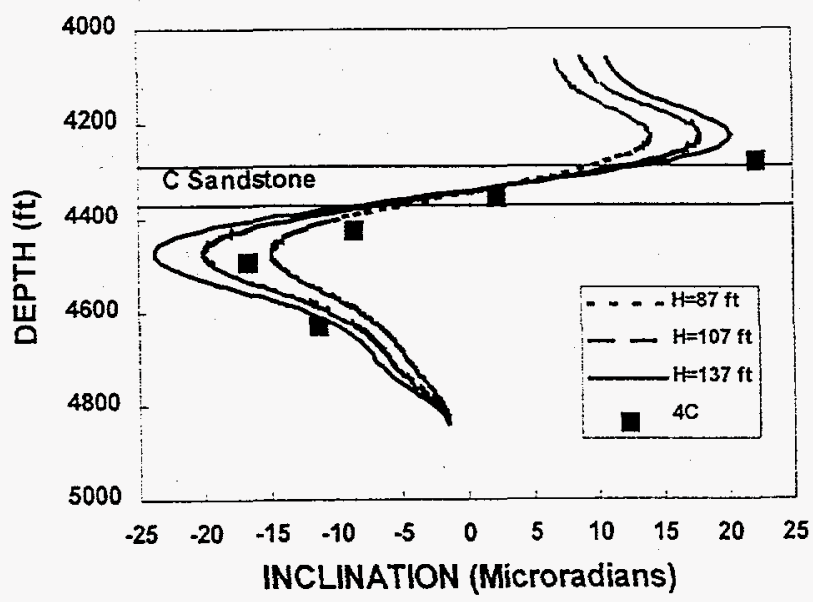

Figure 14. Injection $4 C$ inclination results (2-D Finite Element).
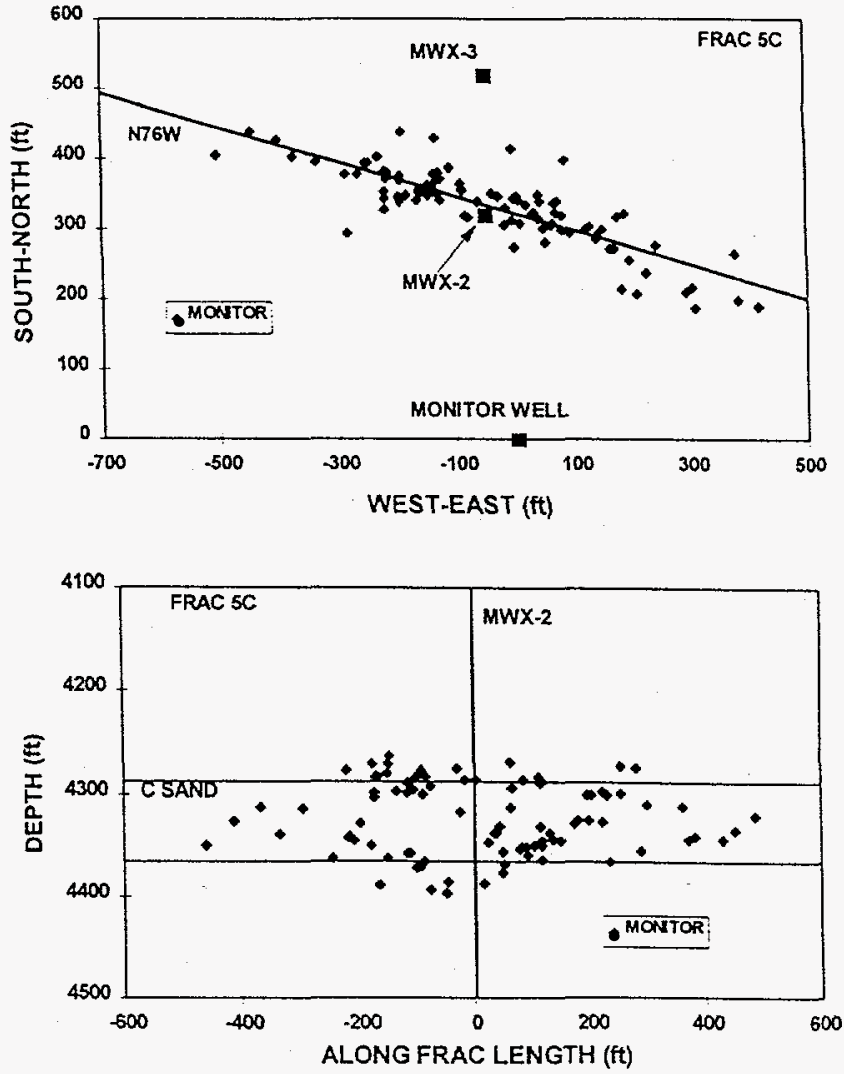

Figure 15. All injection $5 \mathrm{C}$ microseisms.
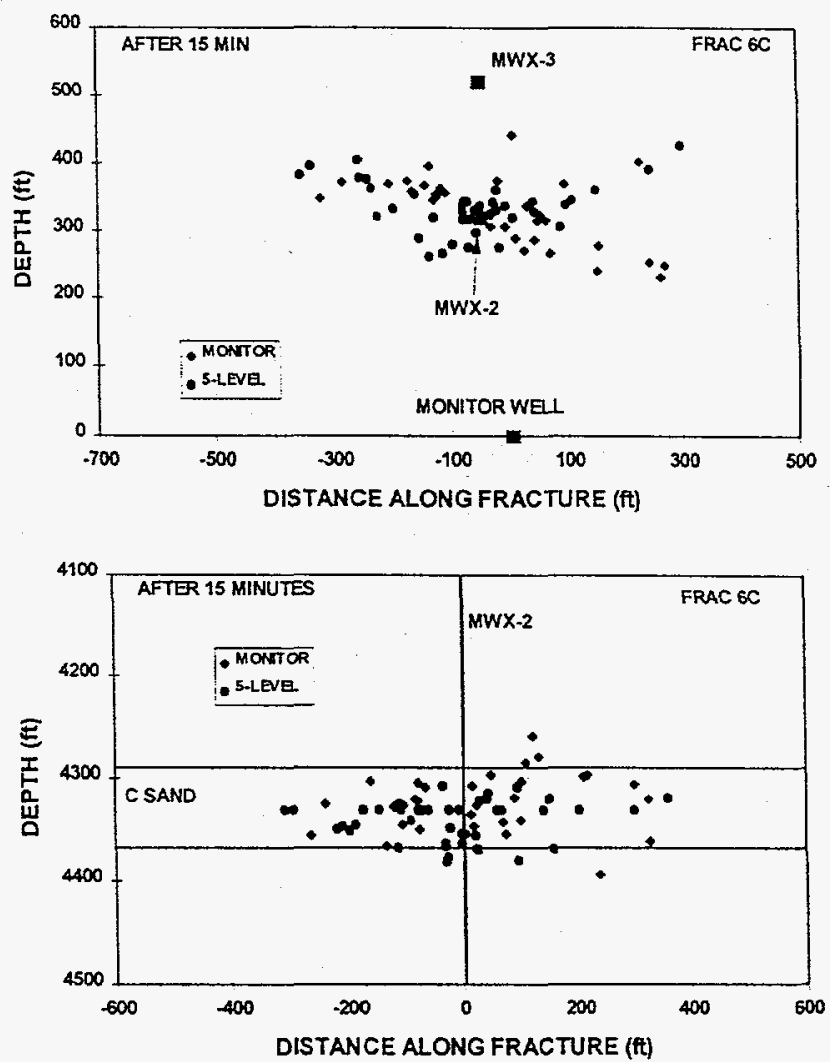

Figure 16. Injection $6 \mathrm{C}$ microseisms after 15 minutes of injection 

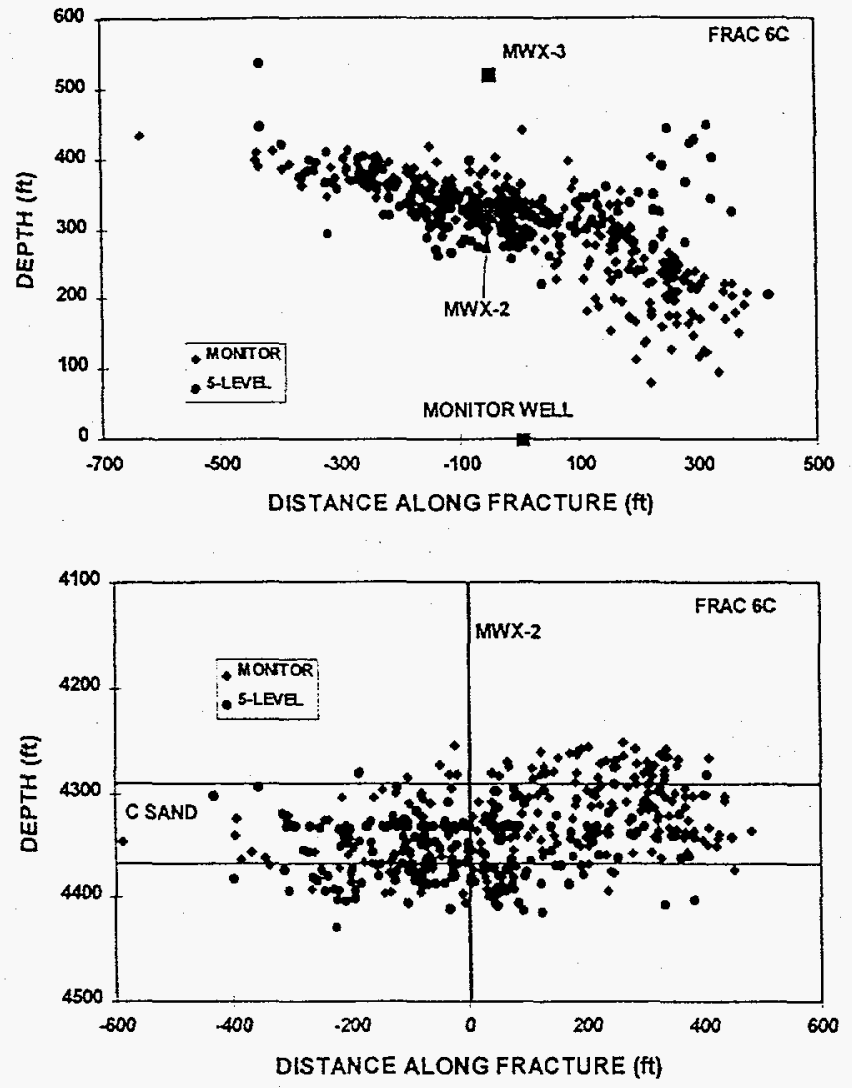

Figure 17. All injection $6 \mathrm{C}$ microseisms.

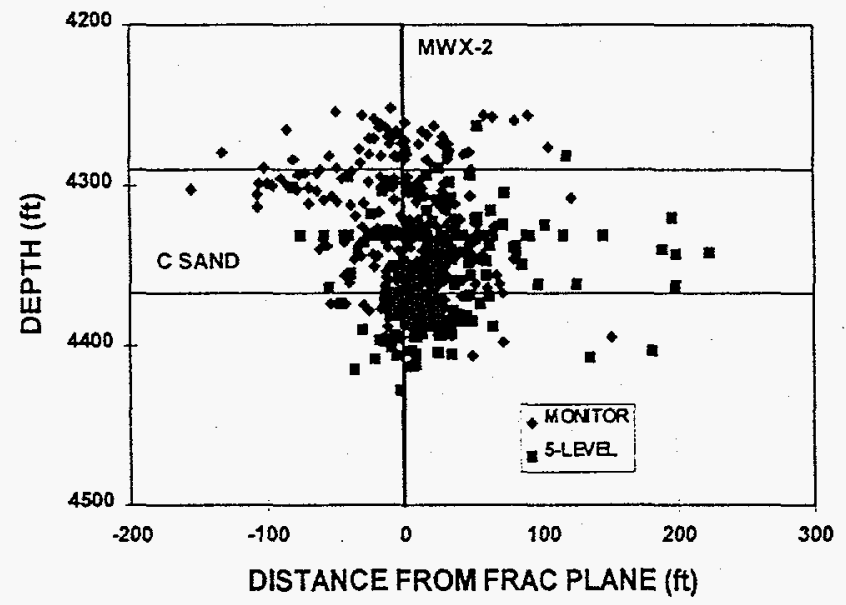

Figure 18. Edge-on view of all $6 \mathrm{C}$ microseisms.

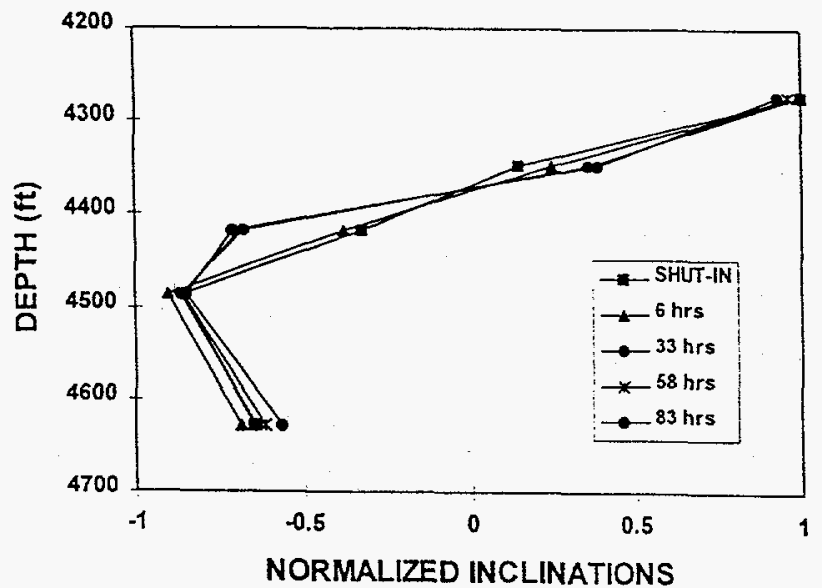

Figure 19. Inclination distribution through closure.

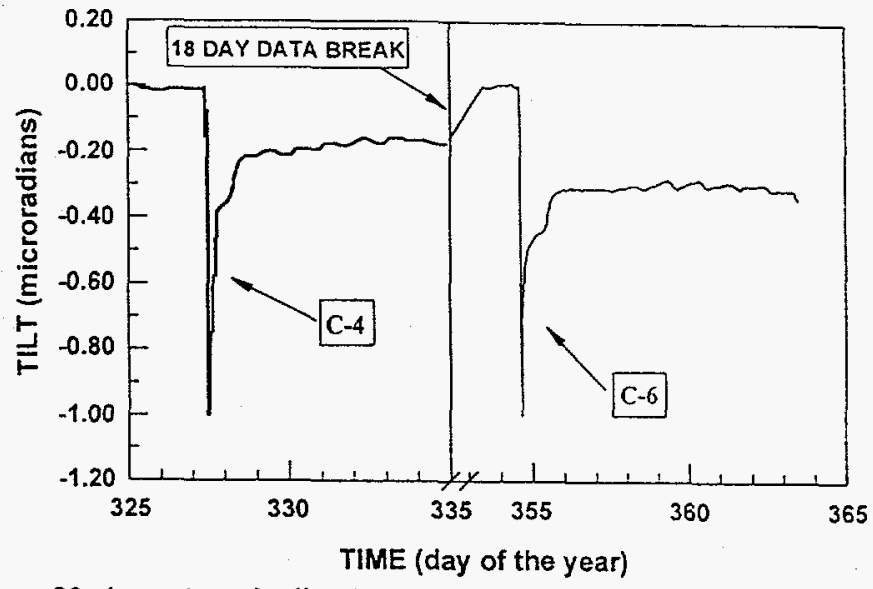

Figure 20. Long-term inclinations after $4 \mathrm{C}$ and $6 \mathrm{C}$ treatments 